\title{
First in line for robotic surgery: Would you want to know?
}

\author{
Y. Joseph Woo, MD, ${ }^{\mathrm{a}}$ John R. Handy, Jr, MD, ${ }^{\mathrm{b}}$ and Robert M. Sade, $\mathrm{MD}^{\mathrm{c}}$
}

\footnotetext{
From the ${ }^{\mathrm{a} D e p a r t m e n t ~ o f ~ C a r d i o t h o r a c i c ~ S u r g e r y, ~ S t a n f o r d ~ U n i v e r s i t y ~ S c h o o l ~ o f ~ M e d i c i n e, ~ S t a n f o r d, ~ C a l i f ; ~}{ }^{\mathrm{b}}$ Providence Cancer Institute, Portland, Ore; and ${ }^{\mathrm{c}}$ Department of Surgery and Institute of Human Values in Health Care, Medical University of South Carolina, Charleston, SC.

Read at the 44th Annual Meeting of the Western Thoracic Surgical Association, Goleta, California, June 27-30, 2018.

Received for publication Nov 2, 2018; accepted for publication Nov 10, 2018; available ahead of print Dec 18, 2018.

Address for reprints: Robert M. Sade, MD, Medical University of South Carolina, 30 Courtenay Drive, Suite 277, MSC 295, Charleston, SC 29425-2270 (E-mail: sader@musc.edu).

J Thorac Cardiovasc Surg 2019;157:1934-40

$0022-5223 / \$ 36.00$

Copyright (c) 2018 by The American Association for Thoracic Surgery

https://doi.org/10.1016/j.jtcvs.2018.11.025
}

The safety, effectiveness, and durability of robotic mitral valve repair have been well documented and, despite increased operating room time, have been found to have some advantages over other repair techniques. ${ }^{1}$ The adoption of robotic mitral valve repair has been widespread in part because of patients' preferences and demands, and in part because of marketing pressures in a competitive health care environment. ${ }^{2}$ As robotic approaches are more widely adopted in response to these factors, the number of surgeons who are relatively inexperienced in robotic techniques increases.

This situation leads to an ethical problem when a patient wants robotic surgery and the surgeon is able to do it but has performed only a limited number of such operations: How much detail about the surgeon's experience must be disclosed during the informed consent process? This question was explored in the form of a debate at the 44th Annual Meeting of the Western Thoracic Surgical Association. The debate was focused on the hypothetical case of a nervous patient.

\section{THE CASE OF THE ANXIOUS PATIENT}

St Sythrypio Medical Center is a 700-bed hospital in a mid-size city; its main competition is the large University Medical Center (UMC) in the same town. At a meeting of the cardiothoracic surgery division 1 year ago, the hospital's business manager reported that he had been tracking the number of cardiac surgical procedures performed at both institutions. The number of mitral valve procedures at St Sythrypio has decreased over the past 3 years, from approximately 30 per year to 20 , whereas the number at UMC has increased by about the same amount. He attributed the difference to the marketing advantage provided by UMC's acquisition of a da Vinci robotic system (Intuitive Surgical Inc, Sunnyvale, Calif) a few years ago, which is now being used for mitral valve surgery.

After much discussion, the cardiothoracic division made 2 decisions. First, the medical center administration would be heavily lobbied to acquire a da Vinci robotic system, and surgery.

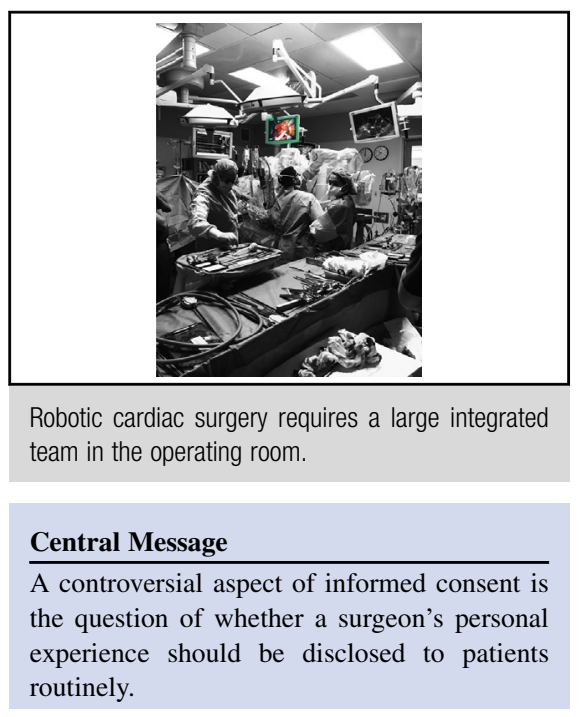

See Commentary on page 1941.

second, once acquired, one of their group would be trained to perform robotic-assisted minimally invasive mitral valve replacement and repair (MIMVR). They designated the youngest surgeon of the group, Dr Hal Asimov, who had been with them for 5 years. He was chosen because he performed both cardiac and thoracic procedures and was generally seen as the best video-assisted thoracoscopic surgeon in the group. He had also been an All-American basketball player in college, had been a champion videogamer throughout his school years, and was an accomplished classical guitarist; all of these characteristics were felt to be predictors of excellence in robotic-assisted

Now, 1 year later, the da Vinci robotic system is in place, and Dr Asimov has been certified by Intuitive Surgical Inc, after training with the da Vinci system on their thoracic surgical simulators and cadavers; he received strongly positive evaluations. In addition, with his entire team, including his assistant surgeon, anesthesiologist, perfusionist, and operating room nurses, he has visited one of the country's largest and most experienced robotic-assisted MIMVR teams and observed several robotic-assisted MIMVR procedures.

Dr Asimov has performed his first case, and it went smoothly, with rapid, uncomplicated postoperative recovery. Another patient presents with severe mitral insufficiency. Bill Chamberlain is a tall ectomorphic man who has had only 1 previous operation many years ago, pectus excavatum repair, including sternal stabilization with a metal bar; thus, sternotomy is a greater than usual risk. 
Although some apprehension is expected, Mr Chamberlain appears extremely anxious, and Dr Asimov is concerned by his history of having been offered MIMVR in a distant city, but faltering at the last minute because of extreme anxiety, far beyond the usual level of apprehension. Since then, the patient has moved to this location and does not want to travel. Because his symptoms have become significantly worse, he urgently needs an operation very soon, and it is clear that the procedure of choice is robotic-assisted MIMVR.

As Dr Asimov plans his preoperative discussion with the patient, he is bothered by one question: Should he tell the patient that he has performed only 1 previous roboticassisted procedure, even if the patient does not ask? Dr Asimov would prefer not to add to the patient's anxiety by telling him this, risking the patient refusing operation again. Is he ethically obligated to inform the patient of his limited experience?

\section{PRO}

\section{Joseph Woo, MD}

Dr Asimov should divulge to the patient his limited experience as part of the informed consent process. In particular, the patient should be aware that he will be undergoing the second robot-assisted MIMVR performed at St Sythrypio Medical Center.

\section{Volume-Outcome Relationship}

In surgery, high clinical volumes, specialized care, and multidisciplinary teams contribute to superior clinical outcomes. ${ }^{3,4}$ As it relates to cardiovascular surgery, Birkmeyer and colleagues ${ }^{5,6}$ published the seminal work demonstrating the inverse relationship between volume and perioperative mortality. Differences in outcome between hospitals may in large part be due to surgeon experience with up to $100 \%$ of differences in outcomes of aortic valve replacement attributable to surgeon volume and $49 \%$ for coronary artery bypass grafting. ${ }^{6}$ The authors concluded that patients would be able to "improve their chances of survival substantially, even at high-volume hospitals, by selecting surgeons who perform the operations frequently."

In mitral valve repair, the likelihood of repair and durability are directly associated with the volume of the surgery. In a report by Chikwe and colleagues ${ }^{7}$ using the New York State database, surgeons performing 25 or more mitral valve repairs per year had significantly lower hazard of reoperation (hazard ratio, $0.45 ; 95 \%$ confidence interval, $0.26-0.76, P=.003) .{ }^{7}$ Indeed, reference centers in mitral valve repair have reported approximately $100 \%$ repair rates for degenerative mitral disease, ${ }^{8,9}$ and national guidelines mandate a greater than $95 \%$ repair rate and less than $1 \%$ mortality rate when operating on patients with asymptomatic primary mitral regurgitation.
In this circumstance, the minimally invasive approach adds an additional layer of complexity. Independent of the surgeon's past experience with conventional approaches, minimally invasive mitral valve repair is a complex operation that is associated with a significant learning curve. Holzhey and colleagues, ${ }^{10}$ reporting on the experience accumulated at the Heart Center Leipzig, demonstrated that a cumulative experience of between 75 and 125 minimally invasive mitral operations was necessary before complication rates declined. Moreover, the volume of operations necessary to maintain good results was approximately 1 per week. ${ }^{10}$

Together, these suggest that the surgeon's experience with the operation is critically important to the patient's ability to make an informed decision about the surgeon performing the operation. Whether this specific surgeon should be performing this operation is unclear given that the surgeon and hospital lack the volume required to develop and maintain proficiency in minimally invasive mitral valve surgery. The patient has a right to know this.

\section{Patient Perspective and Preference}

At the heart of informed consent is the ethical concept of patient autonomy, and this is central to the argument underlying the physician's legal duty to reveal. Before proceeding with an intervention, surgeons are legally and ethically required to provide information that is relevant to the patient's decision ${ }^{11}$ and from the viewpoint of the patient. ${ }^{12}$ The patient's perspective and preferences must be paramount. Recognizing this, the expectation from a legal standpoint is to provide information that is considered adequate for a reasonable person to make an informed decision. ${ }^{12,13}$ Whether surgeon experience should be considered material to a reasonable person from the patient's perspective is then the question.

Char and colleagues ${ }^{14}$ reported the findings from a survey of both surgeons and patients seen in a general surgery clinic regarding the relative importance of various elements of the informed consent process. Part of the survey addressed standard versus innovative approaches (laparoscopic and robotic). Patients routinely (63\%-81\%) considered surgeon experience-including surgeonspecific outcomes, specialized training, and whether it was the surgeon's first time-essential to making an informed decision. Surgeons generally considered their own experience to be less critical to patient decisionmaking underlining the difference in perspective on the information considered to be essential. ${ }^{14}$

\section{Professional Society Guidelines}

Codes of conduct, recommendations, and guidelines from governing bodies and professional societies represent the agglomeration of multiple views on the topic. In their Statement on Principles, the American College of Surgeons 
states that the eligibility to perform operations is incumbent not only on education and training but also on experience and demonstrated proficiency. Despite this, in the recommendations regarding informed consent, there is no requirement to disclose a surgeon's personal experience with a procedure, historical outcomes, or the novel nature of the approach. $^{15}$

Furthermore, the Society of Thoracic Surgeons (STS) and American Association for Thoracic Surgery include in their Code of Ethics that surgeons must make pertinent medical information available to patients enabling them to make informed choices. ${ }^{16,17}$ The STS further specifies that "participants [in the STS adult cardiac surgery database] are encouraged to report their own statistics and outcomes in comparison with the STS national mean or average." 18 However, neither society specifies that surgeon-specific outcomes and experience with an operation represent "pertinent medical information."

\section{Legal Precedent}

The legal precedents set at the state level further confound the controversy. In Johnson v Kokemoor, the Supreme Court of Wisconsin reviewed a case in which a surgeon had only performed 2 basilar bifurcation aneurysms before offering the operation to a patient who subsequently became quadriplegic. The expected difference in morbidity and mortality related to his degree of inexperience compared with a master surgeon was substantial; the patient brought action against the surgeon on the basis of failure to secure informed consent. ${ }^{19}$ In the decision, the court stated that "when different physicians have substantially different success rates with the same procedure and a reasonable person in the patient's position would consider such information material," then the physician's experience is an important element.

In contrast, the Court of Appeals of Washington determined in Whiteside $v$ Lukson that in securing informed consent, a physician does not have "a duty to disclose to the patient information about the physician's experience in providing a proposed treatment." In the case cited, the patient underwent laparoscopic cholecystectomy that was complicated by a common bile duct injury. At that time, the minimally invasive laparoscopic approach was not considered to be standard of care but rather an innovative approach. Despite the physician's limited experience of only 2 prior laparoscopic cholecystectomies, the court determined that the physician's duty to secure informed consent was to disclose treatment-related facts not inclusive of his own experience. ${ }^{20}$

In Duttry v Patterson, the Supreme Court of Pennsylvania was presented with a case in which the surgeon had allegedly misrepresented the volume of esophageal operations he routinely performed. The court found that "evidence of a physician's personal characteristics and experience is irrelevant to an informed consent claim." Although this definition for the doctrine of informed consent limits the actionability of a patient experiencing a complication, it does so only to the extent that such a misrepresentation is irrelevant to informed consent. According to the court, it may be "conceivable that a physician's lack of experience in performing an operation would support a plaintiff's case in negligence." 21

As these relate to our vignette, Dr Asimov's relative inexperience with not only robot-assisted minimally invasive mitral valve repair but also mitral valve surgery in general represents a substantial increase in the patient's risk for suboptimal outcomes. Whether this inexperience is material information in securing informed consent or forms a basis for consideration of negligence will probably remain controversial from a legal standpoint.

\section{Publicly Accessible Data}

The STS has publicly reported hospital quality ratings since 2010. These ratings are based not only on riskadjusted mortality rates but also on clinically relevant performance measures. ${ }^{22}$ The Leapfrog group, a nonprofit watchdog organization, has gone further and is introducing quality ratings based on surgeon volume. For mitral valve operations, the minimum hospital standard is 40 per year and the minimum surgeon standard is 20 per year. ${ }^{23}$

Beyond publicly reported hospital-level quality measures, individual surgeon outcomes are already routinely reported in many states. The Pennsylvania Health Care Cost Containment Council publishes a report of both hospitallevel and surgeon-specific volumes and outcomes. ${ }^{24}$ The New York State Department of Health similarly reports outcomes for cardiac surgery for both hospitals and individual surgeons. ${ }^{25}$ Depending on the state where he practices, Dr Asimov's volumes and outcomes might already be in the public domain. Failure to disclose inexperience to the patient is illogical.

\section{Rationale to Withhold}

In the vignette presented, the patient's extreme anxiety that is "far beyond the usual level of apprehension" may factor into Dr Asimov's decision to withhold volume and experience data. The approach of withholding information that a reasonable patient would want to know contains an element of paternalism that may not be consistent with the patient's preferences or values. Indeed, given the existence of competing centers, the primary reason to omit this information is the fear that the patient will seek care elsewhere. Whether the patient's symptoms and reticence to travel are significant enough to proceed with the operation with Dr Asimov are questions that the patient must decide for himself; business considerations and a surgeon's goals should not factor into this decision. 


\section{Conclusions}

At its heart, this vignette is about the importance of patient autonomy. A critical component of consenting to an operation is determining the surgeon who will perform it. In cardiac surgery, this choice can be the difference between mitral valve repair and mitral valve replacement; it may even be the difference between survival and mortality. Respecting the doctrine of informed consent and patient self-determination, disclosure of relative inexperience with this operation is an ethical obligation. The patient deserves to know.

\section{CON}

\section{John Handy, Jr, MD}

"Anxiety does not empty tomorrow of its sorrows, but only empties today of its strength." Charles Spurgeon, British clergyman, 1834-1892

Dr Asimov should not volunteer his level of minimally invasive mitral valve surgery (MIMVS) experience to this anxiety-ridden patient. A commonly used analytic approach to ethical issues is principlism, which invokes the principles of autonomy, beneficence, nonmaleficence, and justice. ${ }^{26}$ This clinical vignette touches upon the first 3 of these principles.

\section{Informed Consent}

Respect for individual autonomy drove the development and maturation of informed consent after the revelations at the post-World War II Nuremberg war crimes trials. Disclosure is among the 7 components of informed consent, specifically the threshold elements (or preconditions) of competence and voluntariness, the informational elements of disclosure, recommendation, and understanding, and finally, the consent elements of decision and authoriza-

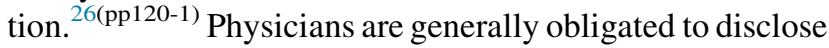
a core set of information, including facts or descriptions that patients usually consider material in deciding on an intervention, information the physician believes relevant, the physician's recommendation, the purpose of seeking consent, and the nature and limits of the authorization.

Professional organizations such as the American Medical Association, Centers for Medicare and Medicaid Services, and the American College of Surgeons address disclosure in informed consent generally and include diagnosis, intervention description, benefits/risks, alternative nonoperative treatments, consequences of declining, and presence and participation of other providers, but do not discuss more detailed nuances of disclosure. ${ }^{15,27,28}$ None recommends addressing the surgeon's personal operative experience.

\section{Disclosure}

Historically, disclosure has been interpreted via 3 lenses or "standards." The first is the professional practice standard or what a reasonable doctor would disclose. The second is the reasonable person standard or what a hypothetical reasonable person would find pertinent and material to deciding about undergoing an intervention. Both have legal standing, but the professional practice standard has become less subscribed to for several reasons, the most important of which is the subversion of the right of autonomous choice. Despite its broad use in many legal jurisdictions, the reasonable person standard also has conceptual and practical difficulties. Empiric studies show that patients use little of the disclosed information before decision making $^{29}$ and that patients generally make their decisions before and independent of the disclosure information. ${ }^{30}$ This is almost intuitive. This almost intuitive, rapid decision making is manifest in the high percentage of patients agreeing to a procedure during the first meeting with the physician, ${ }^{31}$ which surgeons routinely experience.

The third standard, the subjective standard, is the morally preferred and bases the adequacy of disclosure on the specific informational needs of the individual versus a hypothetical standard. ${ }^{26(\mathrm{pp} 123-4)}$ This standard alone meets the need of the patient standing before the caregiver. Thus, disclosure should proceed within the frame of the subjective standard, that which meets the needs of the individual before us.

\section{Nondisclosure?}

This brings us to intentional nondisclosure. Are there circumstances in which nondisclosure benefits the patient? Beneficence is action that is performed for the benefit of others and can include preventing or removing harms. Nonmaleficence is refraining from harmful practice, not acting with malice toward the patient and avoiding even the risk of harm, including physical or emotional injury. ${ }^{32,33}$ The fiduciary relationship of the surgeon to the patient obliges the professional to always, and without exception, favor the well-being and interests of the patient. ${ }^{34}$ Therapeutic privilege states that a physician may withhold information, based on sound medical judgment that divulging the information would potentially harm a depressed, emotionally drained, or unstable patient. Harm includes endangering life, causing irrational decisions, and producing anxiety or stress. ${ }^{26(\mathrm{p} 124), 35}$ The Minnesota Supreme Court ruled it unnecessary to disclose information if likely to cause psychologic harm. ${ }^{36}$ These court decisions are based on the surgeon's duty to benefit the patient and avoid causing harm, in other words, beneficence and nonmaleficence.

\section{Severe Anxiety as Disability?}

The patient, Mr Chamberlain, in the vignette is noted be "extremely anxious." In fact, despite operative indications for proceeding with cardiac valve surgery and initial acceptance of MIMVR "in a distant city," he "faltered at the last minute because of extreme anxiety, far beyond the usual 
level of apprehension." Does extreme anxiety require special recognition and management?

Anxiety has been shown to impair decision making. Anxiety has 2 principal information processing biases: (1) a bias to attend to threat-related information and (2) a bias toward negative interpretation of ambiguous stimuli. In situations with more than 1 potential interpretation, anxiety is associated with a tendency toward a more negative perception. ${ }^{37}$ Animal and human neuropsychologic experiments and neuroimaging studies identify the prefrontal cortex in complex decision making and the negative impact of anxiety on neuronal physiology and decision-making performance. ${ }^{38-40}$ the physiology explaining what every surgeon has occasionally, and frustratingly, encountered. Indeed, the American Psychiatric Association and the World Health Organization recognize anxiety as a "disorder" requiring recognition and tailored management. ${ }^{41,42}$

\section{Patient Safety and Adopting New Medical Technology}

Finally, has Dr Asimov done all he can to maximize his patient's safety? Learning curves have been reported in MIMVR using a right minithoracotomy. ${ }^{43}$ The learning curve of robotic MIMVS is less clear. By using a structured introduction program of robotic MIMVS (extensive prior mitral experience, dedicated team, clinical scenarios, wet laboratories, clinical training, site visits, mentoring), operative efficiency (nonclamp time) improved, but no apparent learning curve was manifest in clamp time, mortality, or morbidity. ${ }^{44}$ In a larger case series, improved operating, cardiopulmonary bypass, and myocardial ischemic times, composite postoperative complications, intensive care, and hospital lengths of stay were improved, but no deaths and excellent echocardiographic results were reported for the entire experience. ${ }^{44}$

Guidelines have been published for the safe introduction of MIMVS, to which Dr Asimov, knowingly or unknowingly, largely adhered. ${ }^{45}$ In a new MIMVS program, it is recommended to select relatively ideal straightforward patients and adopt complexity as program experience and expertise mature. ${ }^{46}$ Surgeons tend to interpret operative complexity in anatomic and physiologic terms, but equally plausibly, difficult psychology or social support can define patient complexity.

\section{Conclusions}

Dr Asimov adopted new technology, a cardiothoracic surgery necessity, ${ }^{47}$ in a safe fashion. His first case went well. His informed consent process should respect Mr Chamberlain's autonomy, while manifesting beneficence and nonmaleficence, not inflame the patient's incapacitating anxiety, thus denying him the effective treatment of his progressive and ultimately fatal cardiac valve pathology, and not volunteer his operative experience. Too much information can cause just as much a problem as too little. ${ }^{26(\mathrm{p} 129)}$

To help the patient cope with his disability, Dr Asimov should request the patient's family and trusted advisors be present at his preoperative discussion and query Mr Chamberlain regarding his preference for disclosure content in the context of his anxiety. He should honor the patient's preference. Dr Asimov should engage in beneficent persuasion with empathy, respect, and negotiation with positive framing. Framing can be accomplished by first sharing the benefits of the surgery, discussing expected outcomes and risks, and finishing by repeating the benefits once more. $^{48}$

However, in deference to Mr Chamberlain's autonomy, if directly asked, Dr Asimov should disclose his operative experience. This disclosure should be positively framed within the context of Dr Asimov's extensive years of intensive training and certifications to become a cardiothoracic surgeon, his prior cardiac surgery experience, his MIMVS program development and training, and his competence, confidence, and dedication to doing his best for his patient, no matter the surgical approach chosen.

\section{CONCLUDING REMARKS \\ Robert M. Sade, MD}

The essayists make convincing cases for their respective positions. Regarding Dr Woo's discussion of the volumeoutcome relationship, the literature on this topic does not answer the question of whether high volumes result in better outcomes or better outcomes lead to higher volumes. Some low-volume programs have excellent results, so whether absence of a high volume of cases in this vignette weighs in favor of Dr Asimov disclosing his caseload is not clear. ${ }^{49}$

Both essayists cite legal decisions in support of their positions. State laws are highly variable with respect to components of informed consent, and outcomes of litigation have supported both points of view. The law seems not to decisively favor one side or the other, so our concern is directed toward the ethics of the situation, which both essayists have addressed persuasively.

They agree that if the patient asks for information about experience and numbers of similar cases, Dr Asimov is ethically obligated to respond fully and accurately. However, Dr Woo asserts that the surgeon should provide the information whether requested or not, and supports that assertion with citations of articles showing that patients desire to have such information; to the contrary, Dr Handy cites literature showing that patients do not actually use disclosed information in making decisions regarding surgery.

The inclination of the learning curve for robotic surgery is also unclear; Dr Woo cites research findings of a steep curve requiring a high volume of cases before complication rates flatten, and Dr Handy cites research that reaches opposing conclusions. 
It seems that both essayists have provided good arguments supporting their positions, while neither has decisively won the debate. Readers must read the texts carefully to reach their own conclusions, which, of course, is the virtual definition of a well-executed debate.

\section{Conflict of Interest Statement}

Authors have nothing to disclose with regard to commercial support.

The authors thank J. Scott Millikan, MD, for moderating the oral debate at the Western Thoracic Surgical Association and for reviewing this article at various stages of its development. Dr Sade's role in this publication was supported by the South Carolina Clinical \& Translational Research Institute, Medical University of South Carolina's Clinical and Translational Science Award Number UL1TR001450. The contents are solely the responsibility of the authors and do not necessarily represent the official views of the National Center for Advancing Translational Science of the National Institutes of Health.

\section{References}

1. Marin Cuartas M, Javadikasgari H, Pfannmueller B, Seeburger J, Gillinov AM, Suri RM, et al. Mitral valve repair: robotic and other minimally invasive approaches. Prog Cardiovasc Dis. 2017;60:394-404.

2. Dixon PR, Grant RC, Urbach DR. The impact of marketing language on patient preference for robot-assisted surgery. Surg Innov. 2015;22:15-9.

3. Handy JR Jr. Attributes contributing to superior outcomes in the surgical management of early-stage lung cancer and examples of implementing improvement. Cancer J. 2011;17:57-62.

4. Handy JR, Costas K, McKenna R, Nisco S, Schaerf R, Stephens K, et al. Regional thoracic surgery quality collaboration formation: providence thoracic surgery initiative. Ann Thorac Surg. 2018;106:895-901.

5. Birkmeyer JD, Siewers AE, Finlayson EV, Stukel TA, Lucas FL, Batista I, et al. Hospital volume and surgical mortality in the United States. N Engl J Med. 2002; 346:1128-37.

6. Birkmeyer JD, Stukel TA, Siewers AE, Goodney PP, Wennberg DE, Lucas FL. Surgeon volume and operative mortality in the United States. $N$ Engl J Med. 2003;349:2117-27.

7. Chikwe J, Toyoda N, Anyanwu AC, Itagaki S, Egorova NN, Boateng P, et al. Relation of mitral valve surgery volume to repair rate, durability, and survival. J Am Coll Cardiol. April 24, 2017 [Epub ahead of print].

8. Castillo JG, Anyanwu AC, Fuster V, Adams DH. A near 100\% repair rate for mitral valve prolapse is achievable in a reference center: implications for future guidelines. J Thorac Cardiovasc Surg. 2012;144:308-12.

9. Goldstone AB, Cohen JE, Howard JL, Edwards BB, Acker AL, Hiesinger W, et al. A "repair-all" strategy for degenerative mitral valve disease safely minimizes unnecessary replacement. Ann Thorac Surg. 2015;99:1983-91.

10. Holzhey DM, Seeburger J, Misfeld M, Borger MA, Mohr FW. Learning minimally invasive mitral valve surgery: a cumulative sum sequential probability analysis of 3895 operations from a single high-volume center. Circulation. 2013;128:483-91.

11. Burger I, Schill K, Goodman S. Disclosure of individual surgeon's performance rates during informed consent: ethical and epistemological considerations. Ann Surg. 2007;245:507-13.

12. Canterbury v Spence. Vol 464: United States Court of Appeals for the District of Columbia Circuit; 1972:772.

13. Veerapen RJ. Informed consent: physician inexperience is a material risk for patients. J Law Med Ethics. 2007;35:478-85.

14. Lee Char SJ, Hills NK, Lo B, Kirkwood KS. Informed consent for innovative surgery: a survey of patients and surgeons. Surgery. 2013;153:473-80.

15. American College of Surgeons Statements on Principles. Available at: https:// www.facs.org/about-acs/statements/stonprin\#iia. Accessed May 23, 2018.
16. Code of Ethics: American Association for Thoracic Surgery. Available at: http:// aats.org/aatsimis/AATS/Association/By-Laws_and_Policies/Code_of_Ethics/CODE OF_ETHICS.aspx. Accessed August 30, 2018.

17. Code of Ethics: The Society of Thoracic Surgeons. Available at: https://www.sts org/about-sts/policies/code-ethics. Accessed August 30, 2018.

18. Guidelines on Use of STS National Database and Database-Derived Information: The Society of Thoracic Surgeons. Available at: https://www.sts.org/about-sts/ policies/guidelines-use-sts-national-database-and-database-derived-information. Accessed August 30, 2018.

19. Johnson v Kokemoor. Vol 545: Supreme Court of Wisconsin; 1996:495.

20. Whiteside v Lukson. Vol 947: Washington Court of Appeals; 1997:1263.

21. Duttry v Patterson. Vol 771: Supreme Court of Pennsylvania; 2001:1255.

22. STS Public Reporting Online: The Society of Thoracic Surgeons. Available at: https://publicreporting.sts.org. Accessed August 30, 2018.

23. The Leapfrog Group. Surgeon Volume and Surgical Appropriateness. Available at: http://www.leapfroggroup.org/surgeon-volume. Accessed August 30, 2018.

24. Cardiac Surgery in Pennsylvania: Information About Hospitals and Cardiothoracic Surgeons (Data: July 1, 2011 to December 31, 2012): Pennsylvania Health Care Cost Containment Council. Available at: http://www.phc4.org/reports/cabg/ 12/docs/cabg2012report.pdf. Accessed August 30, 2018.

25. Adult Cardiac Surgery in New York State: 2013-2015: New York State Department of Health. Available at: https://www.health.ny.gov/statistics/diseases/ cardiovascular/heart_disease/docs/2013-2015_adult_cardiac_surgery.pdf. Accessed August 30, 2018.

26. Beauchamp TL, Childress JF. Moral Norms. Principles of Biomedical Ethics. 6th ed. New York: Oxford University Press; 2009. 13-25.

27. American Medical Association. Informed consent. Available at: https://www ama-assn.org/delivering-care/informed-consent. Accessed May 23, 2018.

28. Center for Medicare and Medicaid Services Revisions to the Hospital Guidelines for Informed Consent. Available at: https://www.cms.gov/Medicare/ProviderEnrollment-and.../SCLetter07-17.pdf. Accessed May 23, 2018.

29. Faden RR, Beauchamp TL. Decision making and informed consent: a study of the impact of disclosed information. Soc Indic Res. 1980;7:313-36.

30. Siminoff LA, Fetting JH. Factors affecting treatment decision for a life threatening illness: the case of medical treatment of breast cancer. Soc Sci Med. 1991;32:813-8.

31. Fetting JH, Siminoff LA, Piantadosi S, Abeloff MD, Damron DJ, Sarsfield AM The effect of patients' expectations of benefit with standard breast cancer adjuvant chemotherapy on participation in randomized clinical trial. J Clin Oncol. 1990;8:1476-82.

32. Ethics fast fact. Beneficence vs. non-maleficence. UCSF School of Medicine Available at: http://missinglink.ucsf.edu/lm/ethics/content $\% 20$ pages/fast_fact bene_nonmal.htm. Accessed May 23, 2018.

33. Ethics at a Glance. Beneficence. Available at: https://rhchp.regis.edu/HCE/ EthicsAtAGlance/Nonmaleficence/nonmaleficence.pdf. Accessed May 23, 2018.

34. Kinsinger FS. Beneficence and the professional's moral imperative. J Chiropr Humanit. 2009;16:44-6.

35. Canterbury v Spence. 464, F.2d 772 (1978).

36. Cornfeldt $v$ Tongen. 262, NW2d 684 (Minn 1977).

37. Harley CA, Phelps EA. Anxiety and decision making. Biol Psychiatry. 2012;72: 113-8.

38. Park J, Wood J, Bondi C, Del Arco A, Moghaddam B. Anxiety evokes hypofrontality and disrupts rule-relevant encoding by dosomedial prefontal cortex neurons. J Neuroscience. 2016:36:3322-35.

39. Park J, Moghaddam B. Impact of anxiety on prefrontal cortex encoding of cognitive flexibility. Neuroscience. 2017;345:193-202.

40. Remmers C, Zander T. Why you don't see the forest for the trees when you are anxious: anxiety impairs intuitive decision-making. Clin Psychol Sci. 2018;6: 48-62.

41. Diagnostic and Statistical Manual of Mental Disorders, 5th Edition-DSM5 Available at: https://www.sciencetheearth.com/uploads/2/4/6/5/24658156/dsmv-manual pg490.pdf. Accessed August 2, 2018.

42. The ICD-10 Classification of Mental and Behavioural Disorders. Available at: www.who.int/classifications/icd/en/bluebook.pdf. Accessed August 2, 2018.

43. Yaffee DW, Loulmet DF, Kelly LA, Ward AF, Ursomanno PA, Rabinovich AE, et al. Can the learning curve of totally endoscopic robotic mitral valve repair be short-circuited? Innovations. 2014;9:43-8.

44. Goodman A, Koprivanac M, Kelava M, Mick SL, Gillinov AM, Rajeswaran J, et al. Robotic mitral valve repair: the learning curve. Innovations. 2017;12:390-7. 
45. Passage J, Edwards J, Almeida A, Fayers T. Guidelines for the safe introduction of minimally invasive mitral valve surgery. Heart Lung Circ. 2013;22:703.

46. Siwek LG, Reynolds B. Totally robotic mitral valve repair. Operative Tech Thorac Cardiovasc Surg. 2007;9:235-49.

47. Swindell JS, McGuire AL, Halpern SD. Beneficent persuasion: techniques and ethical guidelines to improve patients' decisions. Ann Fam Med. 2010;8:260-4.
48. Crumbley AJ, Sade RM. Heart transplant program volume is not a measure of quality. Ann Thorac Surg. 2013;95:1509-10.

49. Yaffee D, Williams M. Cardiac Surgery and the Future. Washington, DC: American College of Cardiology; 2015. Available at: http://www.acc.org/latest-incardiology/articles/2015/09/09/08/44/cardiac-surgery-and-the-future. Accessed May 31, 2018. 